\title{
Algunas reflexiones sobre la concordancia de los tiempos verbales en el lenguaje periodístico de España, México y Perú
}

I ntroducción

En cuestiones lingüísticas, en términos muy generales, se puede presentar menor vacilación a nivel sintáctico, a pesar de las variables sociales o dialectales. En cualquiera o más bien en la mayoría de las lenguas del mundo hay pluralidad de formas estilísticas, por ejemplo en la dicotomía lenguaje escrito y hablado. Es cierto que debe ser más espontáneo y descriptivo analizar el corpus obtenido en los diálogos. Ya que el lenguaje cuenta con varios aspectos, sería una opción tener un enfoque al lenguaje formal o escrito. Por supuesto, puede haber varias formas o estilos.

En este estudio nos limitaremos al lenguaje periodístico, puesto que se puede considerar en mayor o menor grado "formal", cuyo estilo está vinculado seguramente con la norma culta del idioma.

Últimamente hemos observado que en el lenguaje formal, en el periodístico y en el lenguaje hablado de algunas ciudades hispanas, los verbos de las oraciones subordinadas no concuerdan en tiempo con los de las principales. El concepto concordantia temporum en la gramática latina es lo más conocido. De ahí vienen las normas lingüísticas españolas en que ha de existir concordancia de los tiempos entre los verbos principales y los subordinados. Sin embargo, parece haber cierta discordancia. ¿Será el resultado de la evolución lingüística o simplemente una excepción gramatical?

\footnotetext{
* Profesor investigador del Departamento de Estudios del Pacífico, de la Universidad de Guadalajara.
}

La Real Academia Española, en cuestión de la concordancia ${ }^{1}$ de los tiempos en las oraciones subordinadas, indica que se pueden clasificar los casos en dos grupos: el verbo subordinado en indicativo y el otro en subjuntivo. En el primer caso, se puede usar cualquier tiempo en el verbo subordinado a pesar del tiempo del principal: "el observatorio anunció que se acerca a nuestras costas un huracán en dirección NE a so". Cuando el verbo principal es de percepción sensible comover, mirar, oír, escuchar, etcétera, el tiempo del verbo subordinado debe ser paralelo con el principal: "sentí que la enfermera me pinchó"; en este caso, las acciones desentir y pinchar se dan al mismo tiempo.

En caso de que los verbos subordinados se necesiten en subjuntivo, con los verbos de voluntad (mandato, deseo, etcétera), el verbo subordinado puede usarse en cualquier tiempo posterior al del verbo principal: "mandaron que estudie, estudiara o estudiase". Esto se debe al significado de los verbos principales, pues por ejemplo cuando alguien da una orden, la acción que se espera en otra persona debe de realizarse al mismo tiempo o en futuro. Con los demás verbos principales que rigen el subjuntivo, el verbo subordinado puede ir en cualquier tiempo.

\section{Propósito del trabajo y metodología}

El concepto de la "concordancia de los tiempos" hace obligatoria la correlación entre la oración principal y la subordinada. Las oraciones subordinadas pueden ser sustantivas, adjetivas o adverbiales. Según Gili Gaya, las subordinadas sustantivas se clasifican en cinco grupos: 1) sujeto; 2) complemento directo; 3) complemento indirecto; 4) complemento cir- 
cunstancial; 5) complemento con preposición, de un sustantivo o adjetivo. ${ }^{2} \mathrm{Al}$ hablar de esta cuestión, tenemos que admitir que es un tema demasiado extenso. En nuestro caso, por limitación de las cuartillas de esta revista, intentamos referirnos sólo a los dos primeros casos, es decir cuando las subordinadas tienen la función sintáctica de "sujeto" y de "complemento directo".

Tenemos como objetivo principal del presente trabajo reflexionar sobre la concordancia de los tiempos que puedan sufrir los verbos en la oración subordinada. Como ya lo mencionamos, el trabajo está enfocado al lenguaje periodístico de España, México y Perú. Dicho lenguaje, de cierto modo, se podrá considerar como el de la norma culta del español de su respectivo país. Debemos estar conscientes de que este tipo de lenguaje puede diferir del habla o lenguaje hablado, pero creemos que la norma culta lingüística coexiste en ambos lenguajes.

Otro propósito del estudio es determinar de manera hipotética algunas características comunes en el lenguaje periodístico al menos de los tres países hispanohablantes, limitándonos a la mencionada cuestión gramatical. Asimismo, intentaremos observar si existe alguna variación dialectal entre ellos, aunque normalmente el nivel sintáctico presente menor importancia en la variación tanto dialectal como sociolingüística. En otras palabras, sería más difícil detectarlo, porque el sistema gramatical es una parte esencial del idioma y no puede sufrir un cambio drástico de un momento a otro, ni de un lugar a otro.

El método que utilizamos en estas investigaciones fue totalmente bibliográfico porque el lenguaje que nos interesa es periodístico. Tradicionalmente se hubiera hecho este estudio con los periódicos y diarios que se encuentran en las calles o en las bibliotecas. En nuestro caso, aprovechando la comodidad de poder navegar por Internet para recoger estos datos informativos, nos atrevimos a reunir el corpus por medio de las páginas Web de algunas de las empresas periodísticas más rele- vantes en España, México y Perú. Las que se escogieron son www.abc.es (España), www.eloccidental.com.mx (México) y www.elperuano.com (Perú). En este sentido, habrá que decir que tal vez no sea tan exhaustivo como se debería. Pese a esta limitación, podremos decir con confianza que el lenguaje periodístico no ha de exceder de la norma lingüística. Así, pues, muy probablemente podremos obtener información necesaria, aunque en forma global y tentativa.

\section{Análisis de los datos}

\section{Casos de concordancia}

De acuerdo con el resultado de los datos obtenidos, los casos de la concordancia en tiempo resultaron tan sólo con un $23.79 \%$, cuyo porcentaje parece mucho menor de lo que se imaginaba, pues el lenguaje periodístico supuestamente es uno de los estilos más formales que se acercan al lenguaje normativo. En la gramática española tradicional comúnmente se cree que cuando hay concordancia de los tiempos entre el verbo de la oración principal y el de la subordinada - nos referimos al tiempo pasado del verbo principal-, el sujeto subordinado suele coincidir con el principal, como en el ejemplo 1. A pesar de esta norma, en la mayoría de los casos (ver el ejemplo 2) no hubo concordancia de los sujetos (81.25\%), mientras que sólo se registró un $18.75 \%$ del caso coincidente.

\section{Ejemplos:}

1) y explicó [el alcalde] que estaba muy orgulloso de los resultados obtenidos en el 2004, [...] ( $\left.\mathrm{Mx}^{3}, 06 / 01 / 05\right)$.

2) Además, dijo [Otegi] que Batasuna desearía saber la opinión del resto de formaciones y de los gobiernos españoly francés sobre $[\ldots]\left(\mathrm{ES}^{4}, 19 / 01 / 05\right)$.

También hay que advertir que se encuentran algunos casos dudosos de la concordancia de los tiempos entre el verbo principal y el subordinado, aunque en apariencia hay perfec- 
ta concordancia entre ellos. Veamos los siguientes casos:

3) El ejecutivo manifestó que este año la empresa privada aún no reajustó sus precios ( $\left.\mathrm{PER}^{5}, 14 / 01 / 05\right)$.

4) Admitieron que el pasado mes de diciembre, debido a las bajas temperaturas, el número de desprotegidos aumentó, llegando a recibir [...] ( $\mathrm{Mx}$, 18/01/05).

5) Sota Nadal manifestó que en la preparación de este reglamento participaron organizaciones $e$ instituciones educativas [...] (PER, 18/01/05).

El ejemplo 3, según el concepto normativo, no muestra la concordancia adecuada porque "el pretérito en la oración principal exige en la subordinada el imperfecto para la acción simultánea [...], el pluscuamperfecto para la anterior"; 6 es decir, debería decir: reajustaba - había reajustado en vez de reajustó. Además, ya que el adverbio aún se refiere a la "persistencia en el momento en que se habla o de que se habla de cierta acción o estado", ${ }^{7}$ sería más aceptable el uso de dichas formas verbales, al menos desde el punto de vista semántico.

En el ejemplo 4 puede ser un poco dudosa la concordancia en tiempo del verboaumentó con el principal, aunque lo parezca, ya que en esta oración subordinada se está confirmando la idea de la acción de "aumentar" realizada ya el pasado mes de diciembre, la cual indudablemente ocurrió antes del acto de "admitir".

En la oración 5 en apariencia se permite la concordancia de los tiempos entre el verbo principal manifestó y el subordinado participaron; sin embargo, es precipitado interpretarlo de esta manera porque semánticamente el acto de "participar" debe de ser anterior al de "manifestar", por lo tanto debería decir: habian participado. Los verbos subordinados como en los casos 4 y 5 pueden ir en pretérito cuando los verbos principales son de 'percepción': vi que pasaban pasaron, ${ }^{8}$ pues las accio- nes del verbo principal y del subordinado se realizan en el mismo tiempo.

Respecto a los verbos principales, el más usual fue decir, luego le siguen anunciar, recordar, sugerir, explicar, manifestar, mencionar y advertir. Entre otros, se registraron asegurar, expresar, pensar, señalar, sostener, revelar, admitir, observar, añadir, reconocer y bastar. Debido a la naturaleza del lenguaje periodístico, la mayoría de los verbos tienen cierta relación con la forma de "expresarse del sujeto", aunque haya variedad de matiz entre unos verbos y otros.

En la mayoría de los casos, como los verbos son transitivos, se requiere la oración subordinada como complemento directo. Hubo pocos casos (6 y 7) en que dicha oración tenía función de sujeto.

6) Para lograr este nivel cambiario, bastó que los inversionistas apostaran a que la próxima semana [...] (PER, 18/01/ $05)$.

7) Se observó que el precio de la gasolina de 97 octanos se redujo de 14.89 a 14.29 nuevos soles, en promedio, [...] (PER, 19/01/05).

Respecto a la subordinación del ejemplo 7 cabe pensar en dos aceptaciones sintácticas; es decir, se considera "se observó" como "impersonal' la oración sustantiva por "que" puede ser subordinada como complemento directo, pero en caso de considerarlo como voz 'pasiva' la oración que acabamos de mencionar debe ser sujeto.

\section{Casos de discordancia}

Es sorprendente observar que la frecuencia de la discordancia de los tiempos alcanzó un $76.30 \%$, si bien teóricamente se acerca el lenguaje periodístico al normativo. También es interesante mencionar que hubo un alto porcentaje (95.15\%) de la discordancia del sujeto subordinado con el principal. ¿A qué se deberá la última cifra? Citaremos en seguida algunos ejemplos al respecto. 
8) $y$ dijo [el embajador] que "estamos en proceso de formación de más profesionales británicos, pero $[\ldots]$ ".. (ES, 12/01/ 05).

9) Gloria Morales sin embargo mencionó que al concluir su gestión dentro de cuatro meses serán las nuevas autoridades partidistas las que finalmente sancionen [...] ( $\mathrm{Mx}, 20 / 01 / 05)$.

10) En los casos de la ocurrencia de vientos fuertes, aconsejó [el jefe del Indeci] a la población que mejore la seguridad de los techos de calamina, [...] (PER, 15/ 01/05).

En el número 8, semántica y morfosintácticamente no es muy aceptable el caso, sino que se debe de decir "estaban" o incluso "están", ya que el sujeto a que se refiere, tanto por el contexto como por ser $A B C$ una prensa española, ha de ser "los británicos", pero no "los españoles". En el ejemplo 9, desde el punto de vista sintáctico, el verbo subordinado debería de usarse en pospretérito: "sería" en vez de "serâ. Del mismo modo, el verbo subordinado en la oración 10 se usa en presente de subjuntivo en lugar de "mejorara". Según nuestras observaciones, en el habla cotidiana se encuentra mucho menos este desorden sintáctico, aunque en Perú parezca presentarse este fenómeno con cierta frecuencia, quizá mayor que en los demás países en cuestión. ${ }^{9}$
López García afirma que el tiempo "periodístico" es aquel que reúne características del tiempo "físico", "psicológico", "cronológico", "sintáctico" y "morfológico". ${ }^{10} \mathrm{~A}$ nosotros nos parece que en el lenguaje de los diarios predomina el aspecto psicológico como en muchas obras literarias. "Como sólo importa lo que le interesa al lector en el momento de leer la noticia, todos los tiempos tienden a interpretarse desde dicho momento constituido en origen oL (origen del lector)", ${ }^{11}$ cuya idea comprueba que el resultado de estas investigaciones no fue simplemente casual, sino muy aceptable y razonable. En caso de la concordancia de los tiempos entre el verbo principal (en pretérito) y el subordinado, no creemos que los tiempos se hayan medido únicamente desde el origen del periodista, sino que es probable que predomine la norma gramatical.

En lo que concierne a los tiempos de los verbos subordinados, se registraron el presente de indicativo, con $63.11 \%$; el presente de subjuntivo, con $9.71 \%$; el futuro, con $16.50 \%$; el antepresente de indicativo, con $7.77 \%$, y el antepresente de subjuntivo, con $2.91 \%$, respectivamente. Desde el punto de vista dialectológico, se puede observar en el siguiente cuadro cierta variación - o por lo menos preferencia- en estas tres zonas estudiadas.

El tiempo presente, de acuerdo con nuestros datos, tuvo mayor uso en Perú, con $84.21 \%$;

Frecuencia del uso según los tiempos verbales y las zonas (en caso de la discordancia)

\begin{tabular}{llrrrr}
\hline Tiempo del verbo & Ind. I & & & \\
subordinado & sub. & España & México & Perú & Generalidad \\
\hline Presente & ind. & $63.83 \%$ & $50.00 \%$ & $68.42 \%$ & $63.11 \%$ \\
Presente & subj. & $8.51 \%$ & $0 \%$ & $15.79 \%$ & $9.71 \%$ \\
Futuro & ind. & $10.64 \%$ & $44.44 \%$ & $10.53 \%$ & $16.50 \%$ \\
Antepresente & ind. & $12.77 \%$ & $5.56 \%$ & $2.63 \%$ & $7.77 \%$ \\
Antepresente & sub. & $4.25 \%$ & $0 \%$ & $2.63 \%$ & $2.91 \%$ \\
Total & & $100 \%$ & $100 \%$ & $100 \%$ & $100 \%$ \\
\hline
\end{tabular}


le siguieron España, con 72.34\%, y México, con $50 \%$. Lo más sorprendente fue el uso del futuro, pues en México, al igual que en otras zonas hispanoamericanas, prefieren la forma perifrástica "ir $a+$ infinitivo». ${ }^{12}$ En México el uso alcanzó $44.44 \%$, cuya frecuencia es mayor que en los demás países, pero no significa de ninguna manera que esta cifra no sea confiable. Debemos estar conscientes de que el resultado puede variar dependiendo del estilo del lenguaje, del enfoque o metodología, y del corpus obtenido en las investigaciones. El antepresente en España tuvo más incidencias; sin embargo, no nos parece que el uso sea exclusivo de esta zona.

En cuanto a los verbos principales, hubo más incidencias en decir; le siguen asegurar; afirmar y explicar; subrayar y negar; aseverar, sostener, comentar, agregar, reiterar, manifestar, referir; considerar, precisar, desear, anunciar, recordar, revelar, precisar, indicar, destacar, informar, señalar, mencionar, y otros 17 verbos.

\section{Conclusiones}

De acuerdo con el resultado de nuestras investigaciones, en el lenguaje periodístico la discordancia de los tiempos verbales parece muy generalizada, a pesar de su pequeña variación dialectal. En otros términos, podemos señalar la vitalidad de discordancia de la siguiente manera: $83.93 \%$ (en España) $>74.51 \%$ (en Perú) $>64.29 \%$ (en México). Sin embargo, los porcentajes y este orden de la frecuencia tal vez hubieran variado en menor grado según el corpus. De todos modos, no creemos que la variación dialectal sea significativa en este caso.

Desde el punto de vista semántico, en el lenguaje periodístico los verbos principales en el tiempo "pretérito", al menos en algunas ocasiones, parecen adquirir cierto valor de 'presente' o 'antepresente', ya que el lenguaje de los diarios tiene mucho que ver con el enfoque del lector en cuanto a la visión del tiempo. De hecho, el último tiempo gramaticalmente permite cualquier tiempo verbal en la oración subordinada. En este sentido, el fenómeno de discordancia puede ser aceptable. En forma de conclusión tentativa podemos decir que el lenguaje periodístico tiene su propia norma, tanto lingüística como psicológica.

\section{Notas}

1 Real Academia Española. Esbozo de una nueva gramática de la lengua española. Madrid: Espasa-Calpe, 1974, pp. 518-520.

2 Gili Gaya, Samuel. Curso superior de sintaxis española. Barcelona: Biblograf, 1979, pp. 286-299.

3 Esta sigla representa el diario mexicano El Occidental.

4 Esta sigla se refiere al diario español $A B C$.

5 Esta sigla se refiere al diario oficial de Perú El Peruano.

6 Martínez Amador, Emilio M. Diccionario gramaticaly de dudas del idioma. Barcelona: Ramón Sopena, 1973, p. 344.

7 Moliner, María. Diccionario del uso del español: $A-G$. Madrid: Gredos, 1979, p. 303.

8 Suñer, Margarita y José Padilla Rivera. "Concordancia temporal y subjuntivo", en I. Bosque (ed.) Indicativo y subjuntivo. Madrid: Taurus Universitaria, 1990, pp. 185-201.

9 Lipski afirma que en el español de Perú "un verbo principal en pasado puede ir seguido por un subjuntivo en presente: Él quería que lo hagamos" (Lipski, John M. El español de América. Madrid: Cátedra, 1996, p. 346).

10 López García, Ángel. Escritura e información. La estructura del lenguaje periodístico. Madrid: Cátedra, 1996, pp. 76-79.

11 Ibid., pp. 81-82.

12 Según Moreno de Alba, en la lengua hablada se registraron el $50 \%$ de frecuencia en la forma perifrástica; el $25 \%$ con el presente con valor de 'futuro', y el $25 \%$ con el futuro (Moreno de Alba, José G. El español en América. México: Fondo de Cultura Económica, 1988, pp. 175-176). חบ?

Para consultar otros números de la revistaMéxico y la Cuenca del Pacífico, ingresar a la página de Internet: http://publicaciones.cucsh.udg.mx/pperiod/pacifico/index.html 